\title{
Introduction: Searching for the Natural Origins of Content
}

\section{Challenging Research Project or Benighted Quest?}

\author{
Daniel D. Hutto ${ }^{1} \cdot$ Glenda Satne $^{1,2}$
}

Received: 22 July 2015 / Accepted: 22 July 2015 /

Published online: 24 October 2015

(C) Springer Science+Business Media Dordrecht 2015

\begin{abstract}
This paper introduces this special issue which is focused on its target paper - The Natural Origins of Content. The target paper has had a robust and considered set of fifteen replies; a literal A to Z of papers (from Abramova's to Zawidzki's). This extended introduction explains the background thinking and challenges that motivated the target article's proposed research programme. It also provides a sneak peak preview and navigational aid to the special issue's contents. Brief highlights of each commentary are provided and they are grouped together under broad headings. We do not attempt to give detailed replies to these suggestions or answer the various critiques at this stage of the proceedings: that is for future work.
\end{abstract}

Keywords Radical Enactivism $\cdot$ Hard Problem ofContent $\cdot$ Mental Content $\cdot$ Naturalism . Mental Representations · Biosemantics · Neo-Pragmatism · Intentional Stance

"You can please some of the people all of the time, you can please all of the people some of the time, but you can't please all of the people all of the time"

- John Lydgate

\section{The NOC Programme}

The target article of this special issue, 'The Natural Origins of Content' (NOC), attempts to motivate a new research programme for understanding the place of intentionality and content

Daniel D. Hutto

ddhutto@uow.edu.au

Glenda Satne gsatne@uahurtado.cl

1 School of Humanities and Social Inquiry, Faculty of Law, Humanities and the Arts, University of Wollongong, Wollongong, New South Wales 2522, Australia

2 Department of Philosophy, Alberto Hurtado University, Alameda 1869, 3rd floor, Santiago, Chile 
in nature. It revives Haugeland's conceit, from his 1990 classic 'Intentionality All Stars', which likens the game of naturalizing content to a baseball game and identifies three main strategies that the All Star team in field employs against the Sceptics, who are perpetually up at bat. The team's bases are occupied by different types of players: neo-Cartesians are on first; neo-behaviourists are on second base; and neo-pragmatists are on third. Using this device, the target paper makes the case that both the game of naturalizing content and how it is standardly played needs rethinking. We argue for this by: (1) casting a fresh eye over the current state of play on each of the bases; (2) diagnosing the root causes of the fundamental, progress-thwarting problems that have prevented the All Stars from winning the game to date; and (3) recommending that better use be made of the existing resources at each base to play a possibly more winnable game by playing it slightly differently.

\section{Why NOC?}

A deeper motivation for seeking a fresh approach for thinking about the natural origins of content stems from a worry articulated by Hutto and Myin (2013): the Hard Problem of Content (or HPC). The HPC exposes the incompatibility of positing informational content while embracing explanatory naturalism. This reveals that what many philosophers and cognitive scientists call 'informational content' appears to be no kind of content at all. This observation is based on two important assumptions: (1) that the only scientifically respectable notion of information is that of nomic covariance of some sort; and, (2) that nomic covariance isn't any kind of content. Even diehard representationalists readily admit this, but they fail to draw the full consequences of that admission (see Harvey 2015 for a detailed discussion). What follows from acknowledging that covariance isn't any kind of content? Simply this: any science of the mind that is committed to explanatory naturalism and which also employs the notion of informational content must supply another scientifically reputable candidate to explicate that notion. Ultimately, the price of failing to do so is that talk of informational content cannot be taken to be anything more than convenient façon de parler.

Unless the HPC is adequately addressed we have no reason to believe that anything backs up familiar claims that cognitive systems are, in essence, importantly unlike merely physical interacting systems because they literally process informational contents. Close analysis reveals that failure to supply a naturalistic account of informational content either directly undermines the foundations of such theories or forces them to radically reform (See Hutto and Myin 2013, Ch. 4). The implications for the sciences of the mind are quite serious.

Calling the issue 'the Hard Problem of Content' is both justified and rhetorically inspired, given the way it imports the obvious miasma of Consciousness Research into the very heart of Cognitive Science. Hutto and Myin wield it the way the hero wields a wooden stake in a vampire movie. They patiently map out the implicatures of various content dependent approaches, show how each of them cope with various challenges, then they finally hammer the Hard Problem of Content through their conceptual heart (Bakker 2013). 
It is wrong to suppose that naturalising representational content poses only technical problems but neither "deep metaphysical enigmas" (Chalmers 1996, p. 24) nor "any deep philosophical difficulty" (Strawson 1994, p. 44).

For the longest time this was the orthodox view of philosophers of mind. Indeed, in the eighties and nineties it not only looked possible that a workable naturalized theory of mental content might be achieved, the race was on to be the first to get one up and running. Kriegel is probably right to say that "A generation ago ... finding a place for intentionality in the natural order - 'naturalizing intentionality' - consumed more intellectual energy than virtually any other issue in philosophy" (Kriegel 2011, p. 3). But Kriegel is equally right to say that nowadays that research programme has all but petered out. Of course, that is what one would expect had someone reached the finish line - viz. if we now already had a workable naturalized theory of content in our hands. But we do not. Indeed, as Kriegel acknowledges the true explanation is far from triumphalist. It is that: "the naturalizing intentionality research program bears all the hallmarks of a degenerating research program ...[It] has run up against principled obstacles it seems unable to surmount. Far from being technical, the problems just mentioned are fatal" (Kriegel 2011, pp. 3-4).

Even in the face of such failure it is possible to hold fast to the idea that at least some forms of thought and certain kinds of speech acts are contentful in the full-blooded sense of exhibiting reference and truth conditions. Not all thought and speech, to be sure - but at least some or so it seems. If appearances don't deceive then some thoughts and linguistic utterances are contentful. Moreover, the fact that thought and speech are contentful can help us to understand certain important features of human cognition. Assuming this, it is not unreasonable to wonder how this could be so, naturalistically.

But wait a moment! How can anyone who appreciates the force of the HPC simply assume the existence of content so casually? Surely, a detailed alternative naturalistic explanation of content needs to be supplied: one that shows how the HPC can be justifiably circumvented even if it cannot be dealt with in a straightforward fashion. As Van Grunsven (2013) observes what is needed by anyone who assumes a radically enactive and embodied approach to cognition (or REC) is an:

account of how real-time, online forms of environment responsiveness ... is 'scaffolded' into forms of cognition that are able to entertain, say, the absent and the general. Hutto and Myin seem to be aware of this when they explicitly state, "The ultimate task is to explain how basic minds make the development of contentful forms of cognition possible when the right supports, such as shared social practices, are in place" (36). Yet, Radical Enactivism does not offer any substantial views regarding this development. (p. 485).

Campbell (2014) expresses similar dissatisfaction with what is supplied on this score in Hutto and Myin (2013). He writes:

even if existing covariance-based and teleosemantics-based naturalistic theories of content face considerable obstacles (as they admittedly do), it hardly follows that a natural-language-based theory will fare any better. Although Hutto and Myin lambast their opposition for failing to provide properly detailed and adequate explanations of content (142-144, 160), they say 
virtually nothing about how their own natural-language-based explanation would work (Campbell 2014, p. 2, emphasis added).

The challenge articulated by these assessments is a fair one. Indeed, it is the very one that the target NOC article takes the first steps towards answering by preparing the philosophical ground for the necessary work to follow. That said, it only invites confusion to talk of Hutto and Myin's (2013) 'natural-language-based explanation'. While Radically Enactive Cognition (REC) assumes that a capacity for sophisticated linguistic practice is required for having contentful thought and speech, the full explanation of how such forms of speech and thought are possible cannot be based wholly in an account of linguistic practices - this point is repeatedly stressed in the NOC article.

The NOC target paper builds on Hutto and Myin's (2013) idea that the REC approach can salvage some of the core resources from teleosemantics - the most promising naturalistic theory of content to date - by putting them to a different theoretical use. The teleosemantic apparatus, REC holds, can be used to explicate a workable account of contentless basic intentional directedness as opposed to a robust semantic theory of content. This, in turn, puts REC in a position to provide an account of cognition in terms of active, informationally driven, world-directed engagements, where a creature's current tendencies for active engagement are shaped by its ontogenetic and phylogenetic history. Basic minds target, but do not contentfully represent, specific objects and states of affairs. Fundamentally, cognition is a matter of sensitively and selectively responding to information but it does not involve picking up and processing informational content or the formation of representational contents.

The target-focused but contentless notion of Ur-intentionality that these theoretical adjustments to teleosemantics explicate provide a powerful tool for those working in the enactivist framework. It enables enactivists and others to make a clean and radical break with intellectualist ways of thinking about the basis of cognition.

Why then continue to prepare the philosophical ground for the new research programme? Why not, at this point, just let others get down to the relevant scientific work? The answer is simple. Unless some background issues and standard worries are addressed, it is not likely that the challenge will be taken up properly. Worse, any results that may come from such labours are likely to be contested, or at least not fully appreciated. Here it is important to note a number of authors have expressed suspicions that, given certain REC assumptions, any positive attempt to explain content would be inherently flawed and simply doomed to fail.

Harvey (2015), for example, claims that REC embeds an apparent contradiction:

On the face of it, [Hutto and Myin are] contradicting themselves; content doesn't exist in the natural world, and cannot be meaningfully explained in terms of how an organism makes use of a putatively representational entity, but languagedependent cognition is, nonetheless, contentful (p. 113).

There appears to be a contradiction because REC is taken to assume a Default Linguistic Mind, treating "the existence of natural language as both evidence and explanation for content" (Harvey 2015, p. 114, emphasised added). In advancing this reading of REC, Harvey regards Alksnis's (2012) assessment to be both 'succinct and accurate'. The latter states that: 
Hutto and Myin's position relies so heavily on showing that content does not ... emerge from within a naturalistic framework (if at all), the fact that they posit content without specifically tackling the HPC is puzzling. Moreover, it undermines their critique of other appeals to content: if radical enactivism can simply ignore the HPC when it is convenient, then surely any other theory can too. The insistence that language must involve content is no different from the insistence that basic minds must involve content if neither side is backed by an account of how content arises (Alksnis 2012, emphasis added).

Are RECers, uncomfortably, hoist by their own petard in the way Harvey and Alksnis suggest? ${ }^{1}$ Must RECers either (a) face up to exactly the same challenge that we identify as bringing ruin to other accounts or (b) agree that those other accounts equally deserve to be let off the hook? We think not. The fact is that the HPC does not trouble REC in the way it troubles REC's archrival unrestricted CIC - the thesis that Cognition always Involves Content. This is because, pace Harvey, REC does not posit content as a fundamental explanans. Content only enters the REC story at a late stage and has a quite different role earmarked for it than it does in CIC stories. CIC accounts posit mental contents as proposed explanantia, and - as such - mental contents are afforded no special protection from theoretical elimination. Theoretical posits are not givens (e.g., they are unlike life or the universe) - they must earn their explanatory keep. The mental content of CIC stories must be shown to play a non-redundant explanatory role in cognitive science in addition to being able to deal with the HPC. By contrast, all the REC story assumes is that content exists. Like phenomenal consciousness, content, on the REC story has special status as an assumed explanandum. And, as the NOC paper attempts to establish, when content is assumed in the REC framework it is possible to adequately account for its origins with a wider set of resources and in softer, more relaxed ways than are available to defenders of CIC. As an important corrective, and in line with all of this, REC nowhere 'insists' that all language must involve content. It simply takes it for granted that certain thoughts and uses of language - possibly only a very small fraction of the whole - are contentful.

A different worry about the REC approach is that in drawing a distinction between basic, non-contentful and non-basic, contentful minds it introduces a deep discontinuity into the world in a way that is in tension with naturalism. As Menary (2015) paints the picture:

radicals have a problem bridging the gap between basic cognitive processes and enculturated ones, since they think that meaning, or content, can only be present in a cognitive system when language and cultural scaffolding is present (Hutto \& Myin 2013). That, of course, doesn't sit well with evolutionary continuity (p. 3, footnote 5).

Apparently trouble starts if it is assumed that contentful thinking requires mastery of certain socio-cultural practices. That is, it seems there will be problems if it is assumed:

\footnotetext{
${ }^{1}$ To be 'hoist by one's own petard' is to be destroyed by one's own plot or device intended for another.
} 
like Hutto and Myin (2013), that basic minds should not be characterized as representational but that language users take on some of the representational capacities of the language they use; let us call this the saltationist view. On the saltationist view representation is only added on as a consequence of using language, narrative, or possibly some other social resources (Clowes and Mendonça 2015, p. 17).

What's the problem? It is that apparently the so-called "saltationist view poses a chasm between representationally enhanced and more basic minds" (Clowes and Mendonça 2015, p. 18, emphasis added). The puzzle is this: Once a chasm is introduced how then are we to explain continuities? REC assumes that contentful minds have special properties that are not found elsewhere in nature and that contentful minds differ in kind from more basic minds in precisely this respect. Very well. But it hardly follows that the introduction of contentful minds into the world implies a discontinuity in its fundamental fabric - viz. a sort of unbridgeable gap or schism in nature. Why not? The solution proposed by the NOC programme calls on the idea that the construction of socio-cultural cognitive niches enables the establishment of stable practices through which public representational systems emerged. Such socio-cultural practices and cognitive niches are what enable contentful minds to emerge. These assumptions need not imply a discontinuity in nature unless it is also, implausibly, assumed that the existence of such socio-cultural niches implies an inexplicable gap in nature.

Nor does the proposed NOC programme require that "language should do all of the heavy lifting" (Clowes and Mendonça 2015, p. 17). Why not? Simply, because it is assumed that even in cases in which cognition involves content the basis of cognition is enactive and dynamic. Cognition can be content involving without becoming contentbased. Compare: Some conversations involve coffee, some don't. The former do not become coffee-based even if the introduction of coffee into the conversational mix makes a difference and might even have transformative effects on the way such conversations unfold. As it is with coffee, so it is with content. ${ }^{2}$

We fully agree with Clowes and Mendonça (2015), however, in thinking that it "is still a live question as to whether the creation of human minds are wrought from nonrepresentational systems as Hutto and Myin argue" (p. 18). But others regard that very question - the one we want to investigate further - as entirely dead. By their reckoning, there is no choice but to assume that content originates in thoughts which necessarily

\footnotetext{
${ }^{2}$ It is true that both Hutto (2008) and Hutto and Myin (2013) talk in terms of content-based forms of cognition instead of content-involving forms of cognition in places. Admittedly, with hindsight, that way of talking was a mistake. Unfortunately such talk may have given rise to the idea that Hutto and Myin (2013) "subscribe to a genuinely representationalist view of language despite their radicalism about cognition" (Harvey 2015, p. 107, see also Van den Herik 2014). While this misreading may be fostered by our own unfortunate wording, Harvey goes much further when he assumes that Hutto and Myin (2013) "reflexively conceive of everyday language use as necessarily, self-evidently representational [and that we] not only describe language and language-dependent cognition as representational, [but we] suggest that it would be ludicrous to think otherwise" (Harvey 2015, p. 107). These are not views we have ever endorsed. We take it that although there is every reason to suppose that some thoughts and speech acts are contentful in a representational sense, we do not assume that all language is representational. Such attributions to us should not be taken seriously, after all Harvey readily admits that his evidence for ascribing them is marvelously thin because "H\&M don't say much about language. What they do say is mostly in asides and parenthetical statements" (p. 107).
} 
exist before and below socio-cultural practices come on the scene. Even today some influential thinkers take it as read that:

External symbols acquire their meaning from meaningful thoughts - how could it be otherwise? ... [external] symbols [cannot] be meaningful independently of the thoughts they have been designed to express. So, if the Hard Problem spells doom for contentful thinking, it ought to spell doom as well for our abilities to understand and use language (Shapiro 2014, pp. 217-8).

The HPC, on this construal, is a kind of universal acid. To take it seriously at all requires accepting that any and all attempts to explain the natural origins of content and certainly the sort of approach we advocate in the NOC target paper - are doomed to failure. Consequently, a major ambition of the target paper is to defuse this philosophical threat by exposing the questionable nature of its driving assumption - namely, the idea that intentionality always implies content.

\section{Initial Critical Reception}

Lydgate's adage wisely reminds us that you can't please all of the people all of the time. When dealing with philosophers, it is a mark of doing well if you manage to please any of the people any of the time. That's how it should be. Philosophy not only proposes new ideas: it is a form of intense, no holds barred, critical scrutiny of such claims. With that in mind, like young Oliver Twist, we are 'truly thankful' to all our commentators for playing their parts so well. We have had a wonderfully robust and considered set of replies; a literal A to Z of papers (from Abramova's to Zawidzki's) that have critically responded in detail to our target paper in this special issue. By way of a sneak preview and navigational aid to the issue's contents, we give brief highlights of each response below, grouping them together under some broad headings. At the extremes, the commentators recommend quite different approaches to the NOC game - e.g., whether to bother playing it at all or whether it would be best to play a quite different game. All along the spectrum between these extremes, our commentators provide original insights and recommendations about the best way to play the game as NOC construes it - which is often different from the way we recommend trying to play it. We will not attempt to give replies to these suggestions or answer their various critiques at this stage of the proceedings. That is future work.

\section{A Clear Win for the Sceptics!}

In 'The Genealogy of Content or The Future of an Illusion' Alex Rosenberg, advances the view that the illusion that language expresses intentional content is responsible for illusion that thought bears intentional content. Yet once the link between these illusions is exposed - for example, by using the fruits of the sort of analysis offered by our target paper then eliminativism becomes more attractive than the sort of positive relaxed naturalistic project we propose. Analysis of the collective failure of strategies employed on each of the three bases gives us good reason to think that there is no such thing as 
intentional content. Moreover, such an analysis reveals why we are systematically duped into thinking that intentional content exists.

In making his case Rosenberg operates with an opacity criterion for intentionality, one that takes the failure of substitutivity of co-referring terms and co-extensive predicates in the description of an intentional state to be the minimal mark of content. $\mathrm{He}$ also assumes that teleosemantics is not just the best bet for those seeking to naturalise content, it's the only chance they've got. This spells trouble if Darwinian process can't distinguish between extensionally equivalent contents: i.e., if Mother Nature cannot account for the existence of mental states that satisfy the opacity criterion. Putting all of this together reveals a serious problem for anyone who maintains that basic mental contents have essentially the same kind of robust semantic content that gets expressed in linguistic speech acts (a view that is prominently defended by Searle, Fodor, Millikan and many other first basers). This, plus consideration of the other problems faced by those on second and third base, suggest that eliminativist sceptics are in for a win.

Yet what of the target paper's alternative proposal which tries to make use of Urintentionality as a platform for uniting the All Star team and keeping them in the game? Rosenberg recognizes that Ur-intentionality is meant to be something short of fullblooded content but that it is nevertheless a kind of intentionality. He rightly notes that we aim to avoid the determinate content problem by advancing a content-free kind of intentionality. The logic is simple: if fully-fledged, opaque intensional (with-an-s) content is out of reach of teleosemantics, might facts about biological history be able to buy us something less expensive, namely, intentional (with-a-t) content? Rosenberg thinks not. As he sees it Ur-intentionality just couldn't be anything other than indeterminate, opaque content intentionality. And the latter notion is problematic for reasons set out in his paper. Of course, what we sought to provide was a determinate, targeted but wholly contentless form of intentionality. Rosenberg can't see how such an account of Ur-intentionality could possibly make sense of biological error, mistake, and fallibility. The problem seems to be that if Ur-intentionality were truly contentless then it would need to allow for error without falsity - and, on the face of it, that seems impossible. In this light it appears that eliminativism is the word.

Nikolai Alksnis reaches a similar conclusion in 'A dilemma or a challenge? Assessing the all-star team in a wider context'. He focused on the fact that our target paper takes issue with the first base assumption that content appears at the lower rungs in the natural order (or as, Alksnis puts it, that there is 'content all the way down'). Yet it allows for content at the higher rungs, working hard to show that there is a chance of explaining content, more softly, within the fold of socio-cultural practices. Alksnis wonders, however, why the deep problems we identify with naturalising content don't motivate a bleaker assessment of the situation. What, in light of the analysis we provide, justifies thinking that content can be naturalised at all? Why, if we are right about the state of play, is the game of naturalising content even worth playing, at any level or in any form? Advocating a cleaner break with a longstanding tradition he presses for taking seriously the possibility that there may not be any content in the world at all. A more global anti-content approach to cognition, he muses, might put us in a stronger position to honestly and cleanly explain the general nature of intelligence.

Katerina Abramova and Mario Villalobos advocate an equally austere approach in 'Stability and Functional Closure: The apparent (Ur-)intentionality of living beings and 
the game of content'. They broadly support the way the target paper diagnoses and seeks to redefine the problem space but they are not convinced by the details of the proposed solution. In particular they argue for adhering to Strict Naturalism, not a relaxed one, and seek to replace our teleosemiotic Ur-intentionality with an autopoietic theory of living beings.

Abramova and Villalobos see the two main properties of Ur-intentionality as unfit to do the work required of the notion. The kind of specificity Ur-intentionality affords does not suffice for demarcating content, and the sort of directedness which it posits is not intrinsic but only ascribed to living systems. If this is right, then an approach founded on Ur-intentionality will only lead to drawing arbitrary boundaries and taking anthropomorphic projections too seriously. Going the NOC way would not therefore be a good basis for playing any version of the game of naturalizing content. Although Abramova and Villalobos shun standard reductionism and recognize the need to incorporate empirical findings from both the natural and social sciences, they are nevertheless against relaxing the naturalistic attitude. All that needs explaining about linguistic behaviours can be achieved within the frame of Strict Naturalism. This is because although 'living beings are very special and unique [they are still] essentially machines composed of chains of deterministic processes.'

\section{Use Different Tactics at First Base!}

More conservatively, Dimitri Coelho Mollo, in 'Being clear on content', agrees with our basic way of framing the current impasse but thinks that the solution we have in mind falls short of what is needed. While he does not dispute the need for or tenability of the notion of Ur-intentionality, he holds it is simply not variegated enough to do the relevant work in the sciences of the mind that comes before and below truth conditional forms of thought. An intermediate notion of representational content is required. Thus the NOC plan is too austere: it fails to provide all of the kinds of content that are of central importance to cognitive science. Consequently, in addition to explaining the natural origins of Ur-intentionality, neo-Cartesian first basers need to do more. They need to supply an account of the natural origins of contentful states that come between Ur-intentionality and full-blown propositional attitudes. Coelho Mollo argues that in doing so they need not be restricted to teleosemantics; they have other tools to call on.

In 'Intentionality Lite or Analog Content?', Gerard O'Brien and Jon Opie also acknowledge that our analysis of the current state of play is on the money. Focusing on the first base options, they concur that standard format teleosemantic accounts fail to provide workable, proximate explanations of cognition that involve content. They recognize that the vision of content offered by teleosemantic accounts is silent about the role of content in the actual mechanisms of intelligence.

Despite agreeing with the target paper to this extent, O'Brien and Opie deny that an appeal to Ur-intentionality is the right move for taking things forward in any revised framework. For them the trouble is that Ur-intentionality is not up to the task of providing a satisfactory account of cognition because it has too much in common with old school behaviourism. They hold that the only way to explain the 'richness, variety, and specificity of the behaviours that animals exhibit' is to assume the existence of internal states that represent those features in some fashion. After all, they stress, the goal is not merely to understand intentionality but to understand intelligence. 
In sum, O'Brien and Opie agree with us that only two kinds of intentionality need to be distinguished: one weaker and one stronger, where the former can be used to help explain the latter. But they charge our weaker form of intentionality as being too weak, of being too lite on intentionality. In its place they recommend putting a different kind of weak variety of contentful intentionality, one that understands mental representation in structural terms, such that the content of an analog representing vehicle just is the structural resemblance holding between that vehicle and its object.

In 'The Primacy of Skilled Intentionality' Kiverstein and Rietveld argue that the notion of Ur-intentionality suffers in several ways and needs to be replaced with a different notion - that of skilled intentionality if the relevant work is to be done. Yet unlike Mollo and O'Brien and Opie, they don't think that what is needed is a notion of intentionality with content. Instead they seek to motivate an alternative account of how there can be intentionality without mental content, which they call skilled intentionality: it is conceived of as a selective openness and responsiveness to a landscape of affordances.

Kiverstein and Rietveld argue that a notion of skilled intentionality is better placed to do the work earmarked for Ur-intentionality because, unlike the latter, the former places great emphasis on the skill that is involved in responding adequately to environmental affordances. Also, it offers to explain, in a way that Ur-intentionality alone does not, how organisms are open to a whole field of affordances that are selected from the wider landscape of affordances. Finally, they recommend against distinguishing between two different forms of intentionality. Instead, they hold, we should focus on how skilled intentionality takes different forms in different forms of life. They accept that there will be important differences in the way skilled intentionality is deployed in contexts in which questions of truth or correctness can arise and other cases in which all that matters is getting a practical grip on the environment. Nonetheless, they maintain drawing an overly sharp distinction at this juncture between two forms of intentionality may invite trouble.

Anne Jacobson, is a bit more sanguine about Ur-intentionality's chances, in 'Three Concerns about the Origins of Content'. She conjectures that the idea of Ur-Intentionality might be developed into a significant player in philosophy of mind. Yet she harbours some important reservations and makes some useful observations that temper her appraisal. First, like several others, she thinks more needs to be added to the Ur-intentionality account if our proposed adjustment to teleological approaches is going to adequately account for directed intelligence. However, she also notes the reason Ur-intentionality might gain some traction because it is already closer to what cognitive scientists presuppose anyway. As Jacobson sees it the very idea of representational content is a sort of philosophers' invention, it doesn't play a working part in the theories propounded by cognitive science. She holds that cognitive scientists use the term 'representation' in a way that does not imply any kind of content. In some ways echoing yet also disagreeing with O'Brien and Opie, she claims, for example, that the cognitive neurosciences employ notions of similarity - being similar to or being an example of - rather than invoking semantic notions like 'reference' or 'truth'. In this context, she also reminds us that similarity is quite unlike semantic content. For one thing, similarity lacks the sort of specificity required for semantic content. Finally, she notes that focusing too heavily on certain narrative practices alone would adopt an overly restrictive view of human discourse. Appealing to a line strongly defended in feminist thought, Jacobson argues that we need to look at other sociocultural structures too if we are to account for the full gamut of human cognition. 


\section{Focus on Second Base!}

In his 'Dennett's Strategy for Naturalizing Intentionality: An Innovative Play at Second Base', Tad Zawidzki argues that the second base neo-behaviourist strategy approach is stronger and has more resources for playing the game of naturalizing intentionality than is rightfully acknowledged. He sets out the stall for the idea that Dennett's version of this strategy is capable of avoiding "some of the obvious, general problems with neobehaviorism, as well as the problems with the 'first base, neo-Cartesian' and 'third base, neo-pragmatist' strategies". The crucial move is to deny that intentionality is constituted by any natural facts. Doing so avoids the crippling problems that arise for neo-Cartesian accounts. Rather than being the source of some kind of intentionality or content, Zawidzki holds that the right move is to accept only that natural selection produces systems that are interpretable from the intentional stance. Notions such as 'intentional content' can be regarded as abstract idealizations. An apparent advantage of adopting this perspective, is that there is no need to deny ahistorical beings, such as 'swampman', lack intentional states, nor any reason to deny that human infants, nonhuman animals or intelligent machines lack intentionality.

On the Dennettian approach it is still possible to distinguish between full-blown intentionality enjoyed by humans and less complex forms. Doing so, however, differs from drawing a distinction between content-involving intentionality and Ur-intentionality. This is because on Dennett's approach there aren't really two types of intentionality; rather intentionality comes in degrees. This confers another advantage: there is "no deep conceptual or ontological discontinuity between the intentionality of fully competent human language users and other intelligent systems".

Marc Slors, also wants to develop the second base strategy, but in 'Two improvements to the intentional stance theory' he sees the situation differently than Zawidzki. He seeks to show that there are mutual benefits to be gained from Dennett's intentional stance and the NOC approach if the two are more firmly united. He sees advantages in making two main changes to Dennett's strategy. First, contra Zawidzki, he holds that the reality of intentional states should not only be grounded in behavioural patterns but in ascription-independent Ur-intentionality. This guards against the threat that neobehaviourism reduces to 'mere ascriptivism'. Secondly, Slors agrees with the NOC idea that only those that have mastered certain socio-cultural practices are able to adopt the intentional stance. This is important for it allows for the possibility-not open to Dennett - of explaining how people come to adopt the intentional stance non-circularly. Conversely, Dennett's approach supplies resources for fleshing out NOC's "very sketchy research program". As Slors notes, neo-behaviourism is already asked to play a pivotal role in the larger team action. Thus any improvements to Dennett's intentional stance theory will be, at once, beneficial for interpreting and elaborating the NOC proposal. By appropriating the improved version of Dennett's tactics the All Stars improve their overall chances of winning the game.

\section{Focus on Third Base!}

In, 'Content, Control and Display', Kim Sterelny presents an account of how we might understand content and the cognitive role it plays which is broadly sympathetic to the NOC framework. In particular he supports NOC's modest naturalism and its aim to take 
the appearance of mystery out of intentionality by showing how intentional agents arise in the natural world as described by the sciences. He also agrees with NOC's assessment that, as things stand, teleosemantics is far and away the best-developed tool for engaging in such work but that it, nevertheless, has its limits. Teleosemantics alone cannot explain intentional content "if intentional content has the characteristics philosophical theorising standardly takes it to have". Nevertheless, its apparatus can be used to explain "the cognitive platform supporting a raft of our cultural and institutional practices". And such practices, might in turn, enable us to complete the story.

To understand them we need to focus on evolutionary changes in hominin cognition and social life that yielded engineered minds. Unlike the situation of most animals, the biological and cultural evolution of hominins produced mechanisms for collectively and stably transforming cognitive niches across generations. It yielded stable public symbols and practices, e.g., natural languages and systems of mathematical notation, which depend on our capacity to mutually shape one another's minds - stabilising, controlling and making them more predictable over time. This sort of explanation is appropriately a non-magical explanation; given in terms of cranes, not skyhooks - but it is not a hopelessly, overly reductive explanation that tries to make do without cranes at all (Dennett 1995).

Yet while agreeing with NOC at this level of grain, Sterelny's package differs somewhat in the details from NOC's offering. Moreover, Sterelny thinks teleosemantics is right to think of the differences between animal and human cognition as a matter of degree rather than marking differences in kind. ${ }^{3}$ For him, "Complex agents evolved incrementally from simpler ones". Thus he holds that once the origins of our scaffolding practices are explained and "how they work, and what their effects are, we are done. There is no extra problem of then explaining intentional content".

Somogy Varga also thinks third base is where the real action is. In 'Intentionality, Normativity and Naturalism' he recognizes that the NOC programme aims to incorporate both neo-behaviourist and neo-pragmatist strategies within its fold. With this in mind, he highlights potential strengths in both of these approaches that the NOC target paper arguably underplays.

For example, Dennett, he holds can avoid some of the evident difficulties that neobehaviourism faces by arguing, as he does, that what is usually assumed to be original, human intentionality is ultimately derived. Ultimately, this is so because we are designed by natural selection. As such Dennett's appeal to natural selection is quite different from the role it is supposed to play in first base teleosemantic theories of content. In this respect it is closer to the role that NOC earmarks for it.

What sets humans apart from other intentional systems is that "human agents are capable of acknowledging their being bound by standards and recognizing their mistakes as mistakes". And while Dennett's approach needs some help in

\footnotetext{
${ }^{3}$ One of the co-authors of the joint target paper, Satne, holds that the differences in question are in fact differences of degree: the differences that arise through evolution and development that lead from minds incapable of contentful thought to those that are not differences in kind, even though they can be regarded as such. The other co-author, Hutto, sees matters slightly differently. He thinks there really are kind differences in play here but does not suppose such differences imply any unbridgeable schism in nature. Nature, it seems, is full of different kinds of things. There is no need to deny that even if one adopts a thoroughly naturalistic outlook. Either way, however, the contrast between Sterelny's take on these issues and those of defenders of NOC may not be so great, after all.
} 
explicating how this can be so, Varga argues that at this point one can turn to Brandom since he too agrees that human intentionality is derived, but offers more resources for understanding how that is so. Brandom sees the norms needed for understanding the relevant standards as not directly biological but as deriving from social practices. Hence he agrees with NOC that "there is a significant difference between norms maintained by communities of language-users and norms maintained by the processes of natural selection". Thus Varga recommends signing Brandom as a star player on the NOC team, especially as there appears to be a close affinity between NOC's relaxed naturalism and Brandom's non-reductive naturalism. Again what Brandom offers is an explanation in terms of cranes, not skyhooks but to achieve such explanations further work, calling on the resources of, say, anthropology and developmental psychology needs doing. Only then will it be possible "to smooth out any discontinuities". A major task in that vein would be to investigate how the natural origins of community might be explained.

Almost in immediate response to Varga's call, Ian Ravenscroft considers how emotions, understood as contentless, might play a role in enabling us to understand the roots of convention. In his 'The Natural Origins of Convention' he notes that Lewis's theory of convention hits a wall when it comes to supplying a theory of content precisely because it assumes the existence of attitudes that already have content. But, Ravenscroft wonders: Is it possible to develop a theory of convention that doesn't appeal to states with content? In reply he sketches a REC-style account of convention based on contentless basic emotions. Such an account, he holds, needs to explain three key facts about conventions. They are motivating, coordinating and normative. Emotions could potentially explain all of these features of conventions. But if emotions are nothing but contentful attitudes then an emotionalist theory of convention will face the same limitations as Lewis' account. But if some kinds of emotions - basic emotions (anger, disgust, fear, happiness, sadness and surprise) - aren't representational or contentful at all then this provides a foundation for a new theory of convention. Ravenscroft defends the idea that basic emotions can be characterized as affect programs that we are prone to have because we have been 'set up to be set off' by particular aspects of the environment. If such responding can be understood without positing contentful representations, Ravenscroft thinks, a useful parallel might be drawn between an older Humean project and REC's ways of thinking about basic minds.

\section{Admit that the Revised NOC Game isn't (Really) Winnable!}

In, 'Bridging the gap', Olivia Sultanescu argues that the NOC analysis usefully enables a better understanding of the gap associated with our attempt to understand content: NOC manages to re-locate that gap but cannot realize its ambition of actually bridging it. Sultanescu accepts that NOC makes a good case for thinking the real gap is not between the mindless and the minded, but between contentless and contentful forms of mindedness. Still, even if NOC's relaxed naturalism is endorsed and demands of reductionism are weakened, a satisfactory closing of the latter gap is not on the cards.

The NOC analysis may be able to cast some light on how we move from having minds with only contentless intentionality to those that are truly contentful. But even so, the gap between basic and contentful minds cannot be bridged because contentful mentality is of a different kind than contentless mentality. Hence it is not possible to provide a means of completely capturing what comes in between. For example, if we turn to developmental psychology it is not possible to point to a specific moment at which the child transits from 
operating with only contentless intentionality to operating with contentful thoughts as well. As such, the NOC programme cannot account for all of the steps involved in the transition from primitive to full-blown intentionality. If so, "some discontinuity will persist, and a perhaps weaker version of continuity scepticism...must be favoured".

David Macarthur sees the same limitation but recommends, more forcefully, why it should motivate the team to think about playing a radically different sort of game. In 'Liberal Naturalism and Second-Personal Space: A Neo-Pragmatist Response' he argues that the original problem of naturalizing content is the sort of problem that does not admit of a solution. It isn't just hard; it is impossible. He also recognizes that, acknowledging this, it is a major part of the NOC strategy to try to replace the original problem with one that can, in principle, be addressed. Macarthur worries that even the newly conceived problem is not a legitimate problem that can be addressed with the tools on offer.

The ultimate problem is that NOC's Relaxed Naturalism, being a kind of scientific naturalism, "is incapable of acknowledging or recognizing [the] required type of normativity". As Macarthur sees things, the methodological approach of any scientific naturalist must be distinctively third personal, whereas the normativity of content has an ineliminable first person dimension. Hence, no purely third-person scientific approach could possibly do justice to the normativity of content. Thus "even if we shift from reductive to genealogical or connective explanations, the stance of the scientific naturalist, no matter how relaxed, will be incapable of explaining conceptual normativity".

Favouring a more thoroughgoing pragmatist line, Macarthur holds that the only real way forward is to shift from NOC's Relaxed Naturalism to an even more Liberal Naturalism. Only by doing so, he holds, is it possible to make visible the intersubjective reality that arises through communicative relationships in second-personal space. This would be to "adopt a more single-minded strategy of developing the insights of the distinctive outlook of neo-Pragmatism". From this vantage, content and the norms associated with it are not "spooky or queer", even though they can only be explained within a second-personal space by someone to someone who is already sensitive to them.

\section{Play a Quite Different Game!}

In 'Hard Problems of Intentionality' Mark Rowlands suggests going a quite different way than the NOC programme directs. He opens by noting that there are multiple hard problems of intentionality and that the NOC paper has in its sights is either much harder than we suppose or its a pseudo-problem.

NOC's proposed plan for taking things forward, Rowlands holds, is flawed because Ur-intentionality is ill conceived. That being the case there is no chance of getting from Ur-intentionality to content intentionality. The root problem is that Ur-intentionality is meant to be a kind of targeted, extensional directedness reflecting an involvement relation between cognizers and aspects of their environment - objects and states of affairs. But, if Rowlands is right, states-of-affairs must be individuated finely rather than coarsely. He assumes that this requires states-of-affairs to be either identical with, or at least involve, an object falling under a mode of presentation. The same, he holds, is true of facts: a fact is always, at minimum, an object falling under one or more modes of presentation. If so, there cannot be Ur-intentionality without content intentionality.

Crucially, if states of affairs and facts always entail the existence of modes of presentation then the very idea of Ur-intentionality is incoherent and this can be known a priori. 
Yet without Ur-intentionality to inform an understanding of contentless forms of basic cognition and activity, the NOC plan to use neo-pragmatist accounts to explain the emergence of content intentionality is dead in the water. On Rowlands's analysis, mechanisms of social conformation are not even in the ballpark for getting us closer to a better account of the natural origins of content. Why not? As he puts it, "Norms are things to which we conform ... Conforming is a type of doing. Doing is action, broadly construed. And how do we understand this?" The trio of claims he cites is inconsistent just so long as it is assumed that relevant doings are actions that imply the existence of normative mental content of a kind such that it cannot be construed as directed, contentless activity only exhibiting Ur-intentionality. So, once again, if NOC is wrong about the tenability of the notion of Ur-intentionality, then the NOC plan for re-shaping the All Star team is hopeless.

Persuaded by of all of this, Rowlands, recommends rethinking the game even more radically than NOC proposes, and working instead with ideas from the phenomenological tradition in philosophy. That would allow the hard problems of intentionality to be addressed by starting with the objects of directedness (suitably 'epoché-d') and then working backwards to discover the intentional structures of consciousness.

Having now set the stage, it is time to let the game begin. Enjoy the detailed action!

\section{References}

Alksnis, N. (2012). Not radical enough: A reply to Radicalizing Enactivism: How scaffolding fails to solve the hard problem of content. Alderstump. 13 September 2012. http://alderstump.blogspot.com.au/2012_09_ 01 archive.html

Bakker, R.S. (2013). Just plain crazy enactive cognition: A review and critical discussion of Radicalizing enactivism: Basic minds without content. Three Pound Brain. 29 October 2013. https://rsbakker. wordpress.com/tag/enactivism/

Campbell, D. (2014). Radicalizing enactivism: basic minds without content (review). Analysis, 74(1), 174 176.

Chalmers, D. (1996). The conscious mind. Oxford: Oxford University Press.

Clowes, R. W., \& Mendonça, D. (2015). Representation redux: is there still a useful role for representation to play in the context of embodied, dynamicist and situated theories of mind? New Ideas in Psychology. doi: 10.1016/j.newideapsych.2015.03.002.

Dennett, D. C. (1995). Darwin's dangerous idea. New York: Simon and Schuster.

Harvey, M. 2015. Content in languaging: why radical enactivism is incompatible with representational theories of language. Language Sciences 48(2015), 90-129.

Hutto, D. D. and Myin, E. (2013). Radicalizing enactivism: Basic minds without content. Cambridge: MIT Press.

Hutto, D. D. (2008). Folk Psychological Narratives: The Sociocultural Basis of Understanding Reasons. Cambridge: MIT Press.

Kriegel, U. (2011). The sources of intentionality. Oxford: Oxford University Press.

Menary, R. (2015). Mathematical cognition - A case of enculturation. In T. Metzinger \& J. M. Windt (Eds.), Open MIND: 25(T). Frankfurt am Main: MIND Group. doi:10.15502/9783958570818.

Shapiro, L. (2014). Radicalizing enactivism: Basic minds without content (Review). Mind, 123(489), 213220 .

Strawson, G. (1994). Mental reality. Cambridge: MIT Press.

Van den Herik, J., (2014). Why radical enactivism is not radical enough: a case for really radical enactivism. Unpublished Master's thesis. University of Rotterdam, Faculty of Philosophy.

Van Grunsven, J. (2013). Radicalizing enactivism: basic minds without content (review). Faculty Philosophy Journal, 34(2), 483-487. 